\section{Invitation to help compile an index of biodiversity in cities}

SIR — In 2002 the World Summit on Sustainable Development assigned to the Convention on Biological Diversity (CBD) a target for 2010 of significantly reducing the rate of biodiversity loss. If we hope to chart positive trends in biodiversity conservation, then cities must now make a pivotal contribution.

For the first time in history, there are now more people living in cities than in rural areas; cities are likely to become larger, and the number of cities will increase. However, their contribution to the achievement of the CBD's objectives is difficult to measure today. There are tested environmental sustainability and performance indices for countries, but none is applicable to cities. There is therefore an urgent need to compute an aggregate of several indicators of biodiversity conservation for cities.

To enable cities to evaluate their biodiversity conservation efforts better, Singapore proposed that a self-assessment evaluation tool be developed (http://tinyurl. com/q9aj75). This will take the form of an index, devised by the secretariat of the CBD and the Global Partnership on Cities and Biodiversity, and will allow city officials to evaluate their efforts and help them to improve their management of biodiversity.

The index is being designed to be simple, scientifically credible, fair and objective. It focuses on three key components in cities: their indigenous biodiversity; the ecosystem services this provides; and the governance and management of this biodiversity. Balancing a robust number of indicators with manageability led to 26 indicators. Our task-force manual on the computation of the Singapore Index on Cities' Biodiversity will be posted on the CBD website (http://tinyurl. com/lpmwtb).

Most universities are based in cities, so we invite scientists to contribute to this global effort by helping to collect relevant data for the computation of this index. The partnership then aims to table the index for adoption at the 10th meeting of the Conference of the Parties to the CBD in Nagoya, Japan, in October 2010. Data can be e-mailed to L. C.

Lena Chan National Parks Board, Singapore Botanic Gardens, 1 Cluny Road, Singapore 259569 e-mail: lena_chan@nparks.gov.sg Ahmed Djoghlaf Convention on Biological Diversity, 413 R. St Jacques, Suite 800, Montreal H2Y 1N9, Canada

\section{We must reverse the Bush legacy of stem-cell problems}

SIR - Your Editorial 'Stem-cel clarity' (Nature 459, 615-616; 2009) calls for reason in deliberations by the US National Institutes of Health (NIH) on public comments about proposed $\mathrm{NIH}$ guidelines for stem-cell research. We agree that rules barring the use of the 21 previously approved human embryonic stem-cell lines at the US National Stem Cell Bank (NSCB) are bad policy, and stand in the way of scientific progress. We trust that the $\mathrm{NIH}$ will permit use of approved and other lines derived by the US National Academies' standards.

The draft guidelines reignited a contentious issue that dominated the Bush years - the need for a diversity of lines for research and therapeutic use. In 2001, the NIH announced 78 registered lines. In the end, only 21 were available. Our research using data on cellline shipments indicates that fewer federally approved lines are available than is generally believed, and only a handful of those are commonly used (J. McC., J. O.-S. and C.T. S. Cell Stem Cell 4, 107-110; 2009).

No more than 18 cell lines have ever been available from NSCB. The 1,217 unique requests for materials between 1998 and 2008 are quite clustered.
Only three lines - $\mathrm{H} 1, \mathrm{H} 7$ and $\mathrm{H} 9$ - routinely made it to the bench. These three have quickly become experimental standards. Preliminary results from a systematic search of 534 peer-reviewed publications using human embryonic stem-cell lines during the same period show that $\mathrm{H} 9$ was used in $83.3 \%$ of these, $\mathrm{H} 1$ in $60.9 \%$ and $\mathrm{H} 7$ in $24.2 \%$, and that $68.2 \%$ used one or more in combination with other NSCB lines. Also, derivatives of $\mathrm{H} 9$ will be transplanted in the world's first clinical trial for spinal injury.

Over time, researchers routinely discard ill-behaved or less useful lines. But our data raise serious questions about how best to calibrate the number and variety of a controversial research tool that is in short supply. Now that the NIH has made a tentative step towards a coherent national policy, the agency should take a pragmatic approach to the dual problems of diversity and fragmented ethical oversight that are the Bush administration's legacy. The field needs a repository containing an adequate number of high-quality, ethically derived, diverse lines. We must work to ensure availability and widespread use of diverse materials.

Every effort should be made to investigate the provenance of existing lines carefully and expeditiously. Local oversight committees must individually grapple with this time-consuming and exacting task; currently, they often repeat each other's efforts. To avoid redundancy and to speed the accession of new lines, we suggest the creation of a national clearing house specifically charged with certifying provenance. If there are indeed 700 lines worldwide (as the NIH hopes), then this is a necessary step to build a rich and diverse resource that can be used widely and efficiently.

Christopher Thomas Scott Program on Stem Cells in Society, Center for Biomedical Ethics, Stanford University, Stanford, California 94304, USA e-mail:cscott@stanford.edu Jason Owen-Smith Department of
Sociology and Organizational Studies Program, University of Michigan, Ann Arbor, Michigan 48109, USA Jennifer McCormick Departments of Medicine and Health Sciences Research, Bioethics Research Program, Mayo Clinic, and College of Medicine, Rochester, Minnesota 55905, USA

\section{The pleasure and importance of printed journals}

SIR - I am shocked to read in Nature News online that the American Chemical Society intends to stop all personal subscriptions to its printed journals by 2010 , and to start introducing major changes this year ('Chemistry publisher moving towards online-only journals' http://tinyurl.com/llae53).

The attractive printed versions of Journal of the American Chemical Society, Journal of Organic Chemistry, Accounts of Chemical Research and Organic Letters provide distinct advantages in letting me browse their content (during breakfast at home, for example) and readily take in information, without the lengthy opening of individual web pages, article by article.

But I also find this decision to stop the print journals disturbing in my capacity as a board member of the German chemical society, the GDCh, and as head of the editorial board of the journal Angewandte Chemie. I believe that high-quality journals such as Nature and Science and, in chemistry, Angewandte Chemie and Journal of the American Chemical Society should continue to appear in all their published formats, including print. Otherwise, there is a risk that the quality of these prestigious journals could gradually decline to the standard of many of today's web-only journals.

François Diederich Laboratorium fuer Organische Chemie, Department of Chemistry and Applied Biosciences, ETH-Zürich, Hönggerberg HCI G313, 8093 Zürich, Switzerland email:diederich@org.chem.ethz.ch 